\title{
Otimização agroeconômica da cenoura fertilizada com diferentes doses de jitirana ${ }^{1}$
}

\author{
Agronomic and economic optimization of the carrot when fertilized with different \\ dosages of jitarana
}

\author{
Francisco Bezerra Neto ${ }^{2 *}$, Lúcio José de Oliveira ${ }^{3}$, Allysson Pereira dos Santos², Jailma Suerda Silva de Lima² e \\ Ítalo Nunes Silva ${ }^{2}$
}

\begin{abstract}
RESUMO - A utilização de espécies espontâneas do bioma Caatinga como adubo verde tem-se constituído opção importante na produção de hortaliças com o intuito de alcançar o equilíbrio entre aumento na produtividade das culturas e exploração do meio ambiente. O objetivo deste trabalho foi avaliar o uso de diferentes doses de jitirana como adubo verde no desempenho agroeconômico da cenoura em cultivo solteiro. O estudo foi conduzido na Fazenda Rafael Fernandes, distrito de Alagoinha, Estado do Rio Grande do Norte, no período de novembro de 2010 a fevereiro de 2011. O delineamento experimental foi de blocos ao acaso com quatro

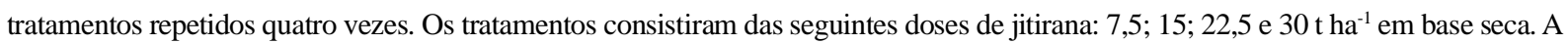
cultivar de cenoura semeada foi a Brasília. As características avaliadas foram: altura de plantas, número de hastes por planta, massa seca da parte aérea e de raízes, produtividades comercial e total de raízes, produtividade classificada de raízes e os indicadores econômicos: renda bruta, renda líquida, taxa de retorno e índice de lucratividade. A otimização do desempenho agroeconômico da cenoura em cultivo solteiro é viabilizada com a incorporação de $13 \mathrm{t} \mathrm{ha}^{-1}$ de jitirana ao solo. O cultivo da cenoura é viável agroeconomicamente com o uso da jitirana como adubo verde.
\end{abstract}

Palavras-chave: Daucus carota. Adubação verde. Espécie espontânea. Desempenho agronômico e econômico.

\begin{abstract}
The use of spontaneous species of the Caatinga biome for green manure has been an important option in the production of vegetables, where the intention is to achieve a balance between increasing crop productivity and exploitation of the environment. The aim of this study was to evaluate the use as green manure of different dosages of hairy woodrose, known locally as jitirana, on the agronomic and economic development of the monocropped carrot. The study was carried out at Fazenda Rafael Fernandes Farm, in the district of Alagoinha, in the State of Rio Grande do Norte, Brazil, from November of 2010 to February of 2011. The experimental design was of randomized blocks with four treatments and four replications. Treatments consisted of the following dosages of jitirana: 7.5, 15, 22.5 and $30 \mathrm{t} \mathrm{ha}^{-1}$ dry weight. The carrot cultivar sown was 'Brasilia'. The evaluated characteristics were: plant height, number of stems per plant, dry weight of the shoots and roots, marketable and total root yield and classified root yield. The economic indicators, gross income, net income, rate of return and profitability index, were also evaluated. The agronomic and economic performance of the monocropped carrot is optimized when incorporating $13 \mathrm{t} \mathrm{ha}^{-1}$ jitirana into the soil. Cultivation of the carrot is agriculturally and economically viable when using jitirana as green manure.
\end{abstract}

Key words: Daucus carota. Green manure. Spontaneous species. Agronomic and economic performance.

\footnotetext{
*Autor para correspondência

${ }^{1}$ Recebido para publicação em 28/05/2012; aprovado em 03/12/2013

Parte da Tese de Doutorado do segundo autor apresentada na UFERSA

2Departamento de Ciências Vegetais/UFERSA, Mossoró-RN, Brasil, 59.625-900, bezerra@ufersa.edu.br, allyssoneng@gmail.com, jailmaagro@ gmail.com, italonunessilva@gmail.com

${ }^{3}$ Instituto Federal de Educação, Ciência e Tecnologia do Ceará, Campus Iguatu, Rodovia Iguatu Várzea Alegre, km 05, Vila Cajazeira, IguatuCE, Brasil, lujoliveira@yahoo.com.br
} 


\section{INTRODUÇÃO}

Atualmente no nordeste brasileiro, alguns produtores vêm utilizando adubos verdes em sistemas de cultivos com hortaliças, como estratégia para aumentar a quantidade de nutrientes no solo, (principalmente nitrogênio, muito exigido pelas hortaliças), aumentar a porcentagem de matéria orgânica do solo e diminuir a acidez do solo e o alumínio tóxico, benefícios esses muito importantes para a sustentabilidade dos sistemas de produção agrícola. A utilização de espécies espontâneas do bioma Caatinga como adubo verde tem-se constituído numa opção importante de produção agrícola para alcançar o equilíbrio entre o aumento na produtividade das culturas e a exploração do meio ambiente. Essas espécies, além de serem adaptadas às condições edafo-climáticas da região, apresentam alta produção de fitomassa, rápido crescimento e estreita relação C/N (LINHARES et al., 2012).

No estado do Rio Grande do Norte, a produção de hortaliças com uso de espécies espontâneas como adubo verde, tais como: Merremia aegyptia (jitirana), Senna uniflora (mata-pasto), e Calotropis procera (flor-de-seda) está começando, porém, algumas pesquisas realizadas com o uso dessas espécies têm evidenciado resultados agroeconômicos promissores com a cultura da alface (BEZERRA NETO et al., 2011; GÓES et al., 2007), rúcula (LINHARES et al., 2009), coentro (LINHARES et al., 2012) e beterraba (SILVA et al., 2011). No entanto, ainda existem vários desafios a serem enfrentados com outras hortaliças, utilizando-se essas espécies como adubo verde, entre elas, a cenoura, hortaliça pertencente à família Apiaceae, do grupo das raízes tuberosas, cultivada em larga escala nas regiões Sudeste, Nordeste e Sul do Brasil (FIGUEIREDO NETO et al., 2010).

Essa raiz apresenta elevado valor nutricional, contendo $\mathrm{K}, \mathrm{Na}, \mathrm{Ca}, \mathrm{Fe}, \mathrm{Mg}, \mathrm{P}$ e $\mathrm{N}$ como fontes minerais além das vitaminas do complexo $\mathrm{B}$, betacaroteno e vitamina C. Em estado in natura é utilizada por indústrias processadoras de alimentos, que a comercializam na forma de seleta de legumes, alimentos infantis e sopas instantâneas, além de ser bastante empregada em refeições escolares e self service (LANA; VIEIRA, 2000). Uma das poucas cultivares adaptada à região semiárida do estado do Rio Grande do Norte é a cultivar Brasília, com excelente padrão de qualidade e elevada produtividade (LOPES et al., 2008).

A jitirana (Merremia aegyptia) é uma planta espontânea que vem sendo usada na adubação de cultivos de hortaliças. Pertencente à família convolvulácea, é uma trepadeira anual, herbácea, com caule cilíndrico, nativa do nordeste brasileiro, encontrada em matas, cercas, clareiras e roçados, se adaptando a solos de diferentes composições granulométricas (BRAGA, 1976; CORREIA, 1984). Tem alcançado produtividade de fitomassa verde em torno de $36 \mathrm{t} \mathrm{ha}^{-1}$, com teores de nutrientes, em termos, de matéria seca de 25,6 $\mathrm{g} \mathrm{kg}^{-1}$ de nitrogênio, 11,0 $\mathrm{g} \mathrm{kg}^{-1}$ de fósforo e 10,6 $\mathrm{g} \mathrm{kg}^{-1}$ de potássio (LINHARES et al., 2012). Se corretamente manuseada na sua qualidade e em termos de quantidade do material a ser utilizado na prática da adubação verde, pode-se constituir numa alternativa importante nos sistemas de produção com hortaliças na agricultura familiar.

Diante do exposto, o objetivo deste trabalho foi avaliar o uso de diferentes doses de jitirana como adubo verde no desempenho agroeconômico da cenoura em cultivo solteiro.

\section{MATERIAL E MÉTODOS}

O experimento foi conduzido na área de pesquisa da Fazenda Experimental Rafael Fernandes, da Universidade Federal Rural do Semi-Árido, em Mossoró-RN, localizada no distrito de Alagoinha, distante $20 \mathrm{~km}$ da sede do município de Mossoró ( $5^{\circ} 11^{\prime} \mathrm{S}$ e $37^{\circ} 20^{\prime} \mathrm{W}, 18 \mathrm{~m}$ de altitude) no período de novembro de 2010 a fevereiro de 2011. O clima nessa região, pela classificação de Köppen, é BsWh, ou seja, seco, muito quente e com estação chuvosa no verão, atingindo temperatura média máxima entre 32,1 e $34,5^{\circ} \mathrm{C}$ e média mínima entre 21,3 e $23,7^{\circ} \mathrm{C}$, sendo junho e julho os meses mais frios e a precipitação média anual em torno de $825 \mathrm{~mm}$.

O delineamento experimental utilizado foi em blocos ao acaso com quatro tratamentos e quatro repetições. Os tratamentos consistiram das seguintes doses de jitirana incorporadas ao solo $\left(7,5 ; 15 ; 22,5\right.$ e $30 \mathrm{t} \mathrm{ha}^{-1}$ em base seca). Cada parcela experimental teve área total de $1,44 \mathrm{~m}^{2}$, com área útil de $0,80 \mathrm{~m}^{2}$. Seis fileiras de cenoura foram dispostas transversalmente em cada parcela, espaçadas entre si de 0,20 m, e dentro da linha de 0,10 m entre plantas, resultando em uma população de 500.000 plantas $\mathrm{ha}^{-1}$. Na avaliação do desempenho da cultura, foi considerado como parcela útil, as plantas das linhas centrais, excluindo-se a primeira e última planta de cada linha e as bordaduras.

O solo da área experimental foi classificado como Latossolo Vermelho Amarelo Argissólico franco arenoso (EMBRAPA, 2006). Antes da instalação do experimento em campo, foram coletadas 20 amostras simples do solo à profundidade de $0-20 \mathrm{~cm}$ e posteriormente homogeneizadas para se obter uma amostra composta, a qual foi enviada para análise ao Laboratório de Química e Fertilidade de Solos do IFCE, Campus de Iguatu, cujos resultados foram os seguintes: $\mathrm{pH}$ (água) $=7,7, \mathrm{M} . \mathrm{O}=4,34 \mathrm{~g} \mathrm{~kg}^{-1}, \mathrm{P}=3,0$ $\mathrm{mg} \mathrm{dm}{ }^{-3},(\mathrm{H}+\mathrm{Al})=0,66 \mathrm{cmol}_{\mathrm{c}} \mathrm{dm}^{-3}, \mathrm{~K}=0,16 \mathrm{cmol}_{\mathrm{c}}$ $\mathrm{dm}^{-3}, \mathrm{Ca}=3,64 \mathrm{cmol}_{\mathrm{c}} \mathrm{dm}^{-3}, \mathrm{Mg}=1,67 \mathrm{cmol}_{\mathrm{c}} \mathrm{dm}^{-3}, \mathrm{Na}$ $=0,029 \mathrm{cmol}_{\mathrm{c}} \mathrm{dm}^{-3}, \mathrm{SB}=5,35 \mathrm{cmol}_{\mathrm{c}} \mathrm{dm}^{-3}, \mathrm{CTCpH} 7=$ $6,01 \mathrm{cmol}_{\mathrm{c}} \mathrm{dm}^{-3}, \mathrm{~V} \%=89$ e $\mathrm{CE}=1,77 \mathrm{dS} \mathrm{m}^{-1}$. 
O preparo do solo da área experimental consistiu de uma gradagem seguida de levantamento dos canteiros. Antes da instalação do trabalho em campo, foi realizada uma solarização de 45 dias dos canteiros de plantio, cuja finalidade foi reduzir a população de fitopatógenos do solo, que viessem a prejudicar a produtividade da cultura avaliada.

A jitirana utilizada como adubo verde foi coletada em diversas localidades da zona rural do Município de IguatuCeará antes do início da sua floração. Após a colheita as plantas foram trituradas em máquina forrageira convencional obtendo-se partículas fragmentadas com granulometria em torno de 2,0 a 3,0 cm, que foram desidratadas sob temperatura ambiente, até atingir o teor de umidade de $10 \%$ e depois submetidas a análises em laboratório, cuja composição química obtida foi: $\mathrm{N}=19,76 \mathrm{~g} \mathrm{~kg}^{-1} ; \mathrm{P}=3,79 \mathrm{~g} \mathrm{~kg}^{-1} ; \mathrm{K}=34,28$ $\mathrm{g} \mathrm{kg}^{-1} ; \mathrm{Ca}=8,93 \mathrm{~g} \mathrm{~kg}^{-1} ; \mathrm{Mg}=5,0 \mathrm{~g} \mathrm{~kg}^{-1} ; \mathrm{S}=1,3 \mathrm{~g} \mathrm{~kg}^{-1} ; \mathrm{Fe}$ $=321 \mathrm{~g} \mathrm{~kg}^{-1} ; \mathrm{Zn}=18 \mathrm{~g} \mathrm{~kg}^{-1} ; \mathrm{Cu}=8 \mathrm{~g} \mathrm{~kg}^{-1} ; \mathrm{Mn}=30 \mathrm{~g} \mathrm{~kg}^{-1} ; \mathrm{B}$ $=38 \mathrm{~g} \mathrm{~kg}^{-1}$ e Na$=169 \mathrm{~g} \mathrm{~kg}^{-1}$ e relação C:N de 25:1.

Foram realizadas duas incorporações do adubo verde, sendo $50 \%$ nos canteiros de plantio no dia 31 de agosto de 2010 (20 dias antes da semeadura da cenoura) e os $50 \%$ restante no dia 15 de novembro de 2010 (55 dias após o plantio da cenoura). Após a incorporação da jitirana ao solo, irrigações diárias foram realizadas em dois turnos com a finalidade de favorecer a atividade microbiana do solo no processo de decomposição.

Plantou-se a cultivar de cenoura Brasília, pertencente ao grupo Brasília, indicada às condições climáticas da região Nordeste (LOPES et al., 2008). Essa cultivar apresenta folhagem verde escura, raízes cilíndricas com coloração laranja clara e baixa incidência de ombro verde ou roxo, resistente ao calor, a requeima por alternaria e ao pendoamento prematuro (OLIVEIRA et al., 2011).

A semeadura da cenoura foi realizada no dia 20 de setembro de 2010, em covas de aproximadamente $3 \mathrm{~cm}$ de profundidade, colocando-se três a quatro sementes por cova. O desbaste foi realizado 23 dias após a semeadura, deixando-se uma planta por cova, totalizando 500.000 plantas $\mathrm{ha}^{-1}$.

Durante a condução do experimento, o controle de plantas daninhas foi realizado através de capinas manuais. As irrigações foram efetuadas por microaspersão, com turno de rega diária parcelada em duas aplicações (manhã e tarde), fornecendo-se uma lâmina de água de aproximadamente $8 \mathrm{~mm} \mathrm{dia}{ }^{-1}$. A colheita da cenoura foi realizada no dia 06 de janeiro de 2011.

As seguintes características foram avaliadas na cenoura: produtividade total de raízes (determinada a partir da massa da matéria fresca das raízes das plantas da área útil); produtividade comercial de raízes (determinada a partir da massa da matéria fresca das raízes das plantas da área útil, livres de rachadura, bifurcações, nematóides e danos mecânicos, expressa em $\mathrm{t} \mathrm{ha}^{-1}$ ) e produtividade classificada de raízes, obtida segundo o comprimento e maior diâmetro transversal das raízes em: longas, com comprimento de 17 a $25 \mathrm{~cm}$ e diâmetro menor que $5 \mathrm{~cm}$; médias, com comprimento de 12 a $17 \mathrm{~cm}$ e diâmetro maior que 2,5 cm; curtas, com comprimento de 5 a $12 \mathrm{~cm}$ e diâmetro maior que $1 \mathrm{~cm}$ e refugo, raízes que não se enquadram nas medidas anteriores (LANA; VIEIRA, 2000).

A renda bruta de cada parcela foi obtida multiplicando-se a produtividade comercial da cultura em cada tratamento pelo valor do produto, que foi de $\mathrm{R} \$ 0,80 / \mathrm{kg}$ de cenoura pago ao produtor no mês de janeiro de 2012. A renda líquida foi obtida subtraindo-se da renda bruta os custos de produção. Foram considerados, custos de produção da cenoura, os preços de insumos e serviços vigentes no mês de janeiro de 2012 na cidade de Mossoró-RN. A taxa de retorno por real investido foi obtida por meio da relação entre a renda bruta e o custo de produção de cada tratamento. $O$ índice de lucratividade foi obtido da relação entre a renda líquida e a renda bruta, expressa em porcentagem.

Análises de variância foram realizadas nas características avaliadas na cenoura e um procedimento de ajustamento de curvas de resposta foi realizado através do software Table Curve, conforme Bezerra Neto et al. (2011) para avaliar cada característica em função das doses de jitirana incorporadas.

\section{RESULTADOS E DISCUSSÃO}

A altura de plantas e massa seca da parte aérea da cenoura aumentou com as doses crescentes de jitirana incorporadas ao solo, alcançando os valores máximos (51,21 cm e 3,64 $\mathrm{t} \mathrm{ha}^{-1}$, respectivamente) na quantidade de jitirana de $30 \mathrm{t} \mathrm{ha}^{-1}$, correspondendo a um incremento de $8,94 \mathrm{~cm}$ e de $1,21 \mathrm{t} \mathrm{ha}^{-1}$ em relação à menor quantidade de jitirana $\left(7,5 \mathrm{t} \mathrm{ha}^{-1}\right)$ (Figuras 1A e 1B). A resposta ascendente dessas variáveis em função do aumento nas doses de jitirana pode ser atribuída ao maior suprimento nutricional das plantas da cenoura, adequada sincronia entre a decomposição e mineralização da jitirana adicionada e a época de maior exigência nutricional da cultura (FONTANÉTTI et al., 2006).

Houve incremento no número de hastes por planta, na massa seca de raízes, na produtividade comercial e total de raízes de cenoura com as doses crescentes de jitirana incorporadas ao solo, até os valores máximos de 11,57, 4,14, 32,11 e 33,02 t ha-1, respectivamente, nas quantidades de jitirana de 18,72 , $13,83,15,54$ e $16,13 \mathrm{t} \mathrm{ha}^{-1}$, decrescendo, em seguida, até a 
última dose de jitirana adicionada (Figuras 1C, 1D, 2A e 2B). Esses valores máximos de produtividade estão na faixa de produtividade média das cenouras no Brasil, que está em torno de 30 a 40 t ha $^{-1}$ (PAULA JÚNIOR; VENZON, 2007). Diante disso, observa-se, que a otimização do desempenho produtivo ou agronômico da cenoura foi obtida com a incorporação da dose de jitirana ao redor de $16 \mathrm{tha}^{-1}$. Essa otimização se deve, em parte, à maior disponibilidade de nutrientes liberados pela jitirana, como também, pela sincronia na qual esses elementos são liberados e absorvidos pela planta.

Sabe-se, no entanto, que a taxa de decomposição de resíduos orgânicos está ligada à relação carbono: nitrogênio $(\mathrm{C}: \mathrm{N})$ do material sob esse processo, que no caso da jitirana é de 25:1, e que a mineralização do $\mathrm{N}$ também é muito influenciada por esta relação $\mathrm{C}$ : $\mathrm{N}$ do material em decomposição (VALE et al., 2004). Assim, com a adição de resíduos com relação $\mathrm{C}: \mathrm{N}$ entre 20:1 e 30:1, não há predomínio de imobilização e nem mineralização de N. Além dessa disponibilização de nutrientes fornecida pelas doses crescentes de jitirana, esses resultados também se deve à influencia que os adubos verdes exercem sobre as propriedades físicas, químicas e biológicas do solo, uma vez que eles apresentam efeitos condicionadores e aumentam a capacidade do solo em armazenar nutrientes necessários ao desenvolvimento das plantas, resultando em maior rendimento de massa.

Para as produtividades de raízes longas e refugo, observou-se também comportamento crescente com o aumento nas doses de jitirana incorporadas, até as produtividades de 18,29 e 1,93 $\mathrm{t} \mathrm{ha}^{-1}$ nas doses de jitirana de 16,51 e 25,20 t ha-1, diminuindo, posteriormente, até a última dose adicionada ao solo (Figuras $2 \mathrm{C} \mathrm{e} 2 \mathrm{~F}$ ). Em relação ao valor máximo da produtividade comercial de raízes de cenoura obtido na dose otimizada, pode-se observar que $56,96 \%$ dessas raízes foram do tipo longa, enquanto que, $5,87 \%$ foram do tipo refugo em relação à produtividade total otimizada de raízes. Para as produtividades de raízes dos tipos médias e curtas, não se ajustaram nenhuma equação de regressão em função das doses de jitirana incorporadas. No entanto, as produtividades médias dessas raízes foram da ordem de 31,6 e 3,09 $\mathrm{t} \mathrm{ha}^{-1}$, respectivamente (Figuras 2D e 2E). Trabalhos de pesquisa têm relatado

Figura 1 - Altura de plantas, massa seca da parte aérea, número de hastes por planta e massa seca de raizes de cenoura solteira em função de quantidades de jitirana incorporadas ao solo
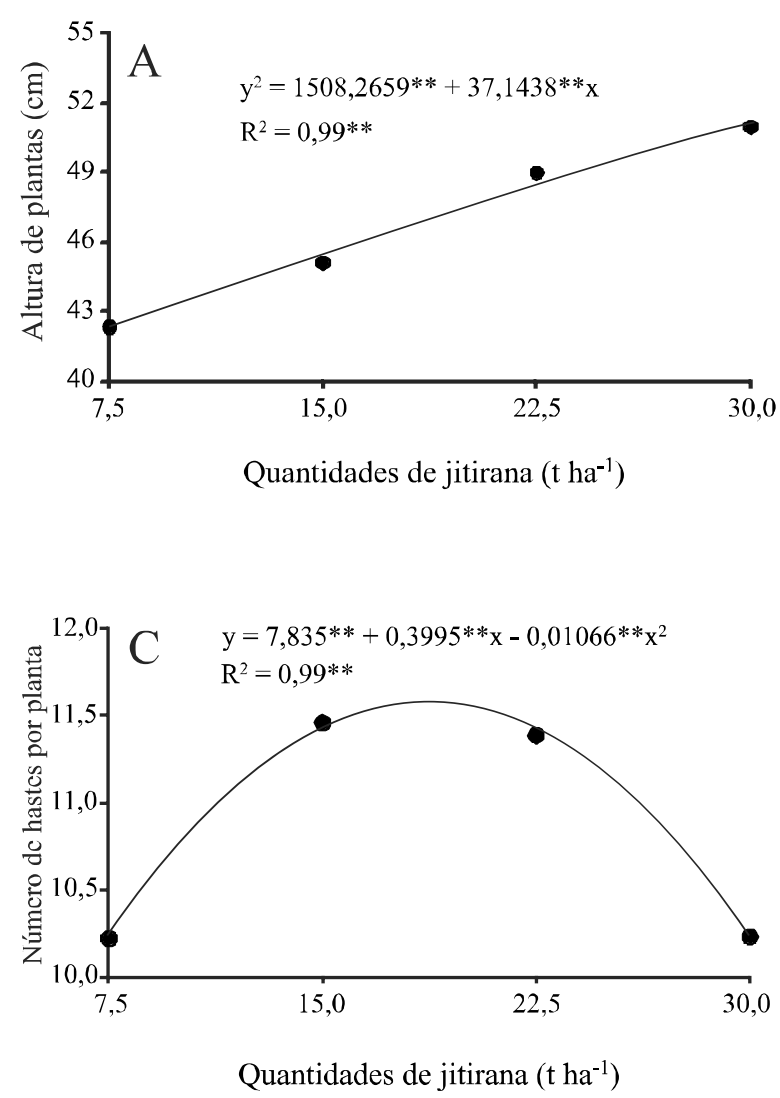
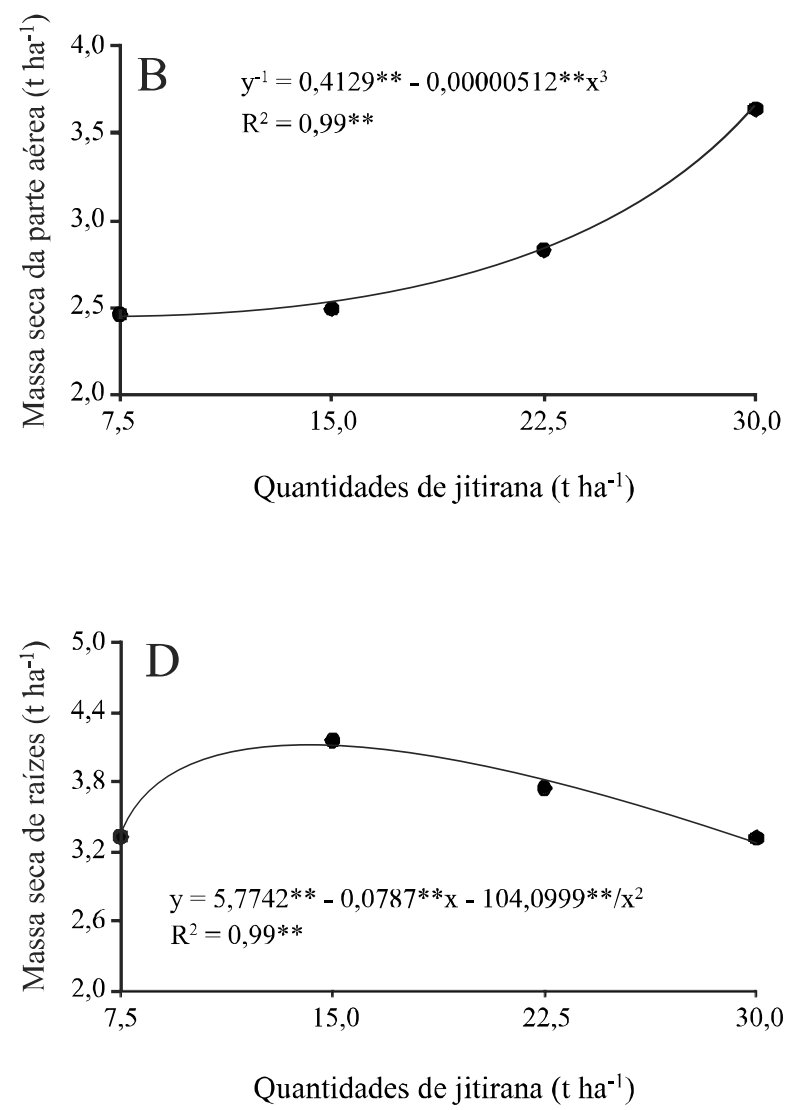
Figura 2 - Produtividade comercial e total de raízes, produtividades de raízes longas, médias, curtas e refugo de cenoura solteira em função de quantidades de jitirana incorporadas ao solo

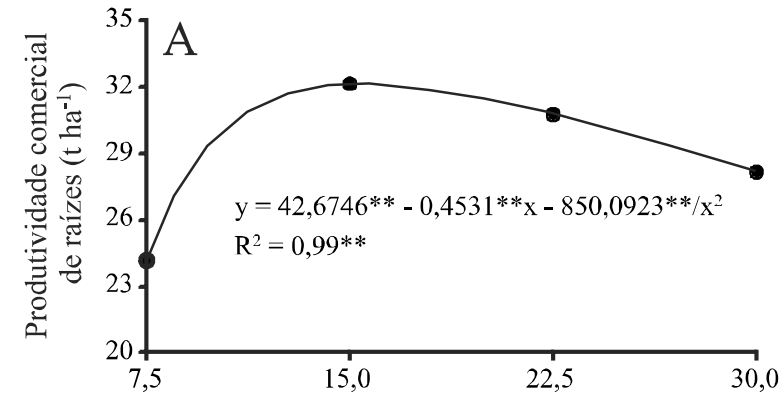

Quantidades de jitirana $\left(\mathrm{t} \mathrm{ha}^{-1}\right)$

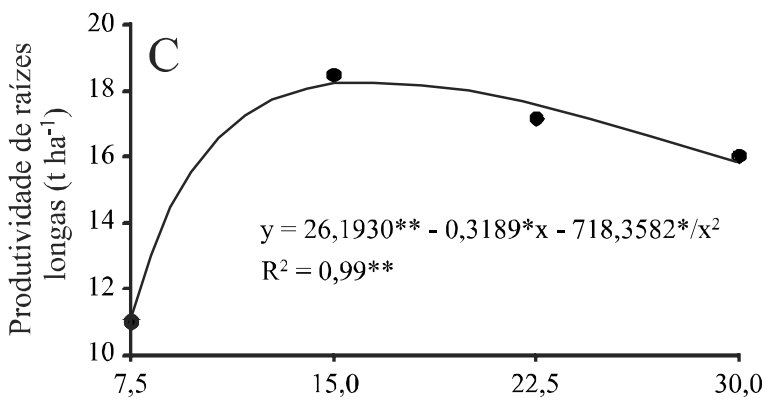

Quantidades de jitirana $\left(\mathrm{t} \mathrm{ha}^{-1}\right)$

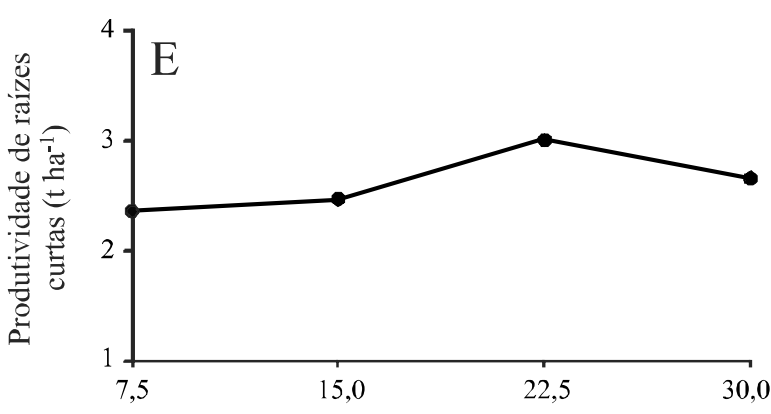

Quantidades de jitirana $\left(\mathrm{t} \mathrm{ha}^{-1}\right)$

que, hortaliças tuberosas respondem muito bem à adubação verde com espécies espontâneas da Caatinga (BATISTA, 2011; MOREIRA, 2011; SILVA et al., 2011).

Com relação aos indicadores econômicos, renda bruta, renda líquida, taxa de retorno e índice de lucratividade, observou-se aumento nos valores com as doses crescentes de jitirana incorporadas ao solo, até os valores máximos de $\mathrm{R} \$ 25667,47$; R $\$ 12974,64 ; 1,97$ por real investido e $49,40 \%$ nas doses de jitirana de 13,$49 ; 12,21 ; 11,55$ e $11,48 \mathrm{t} \mathrm{ha}^{-1}$, respectivamente, decrescendo, em seguida,
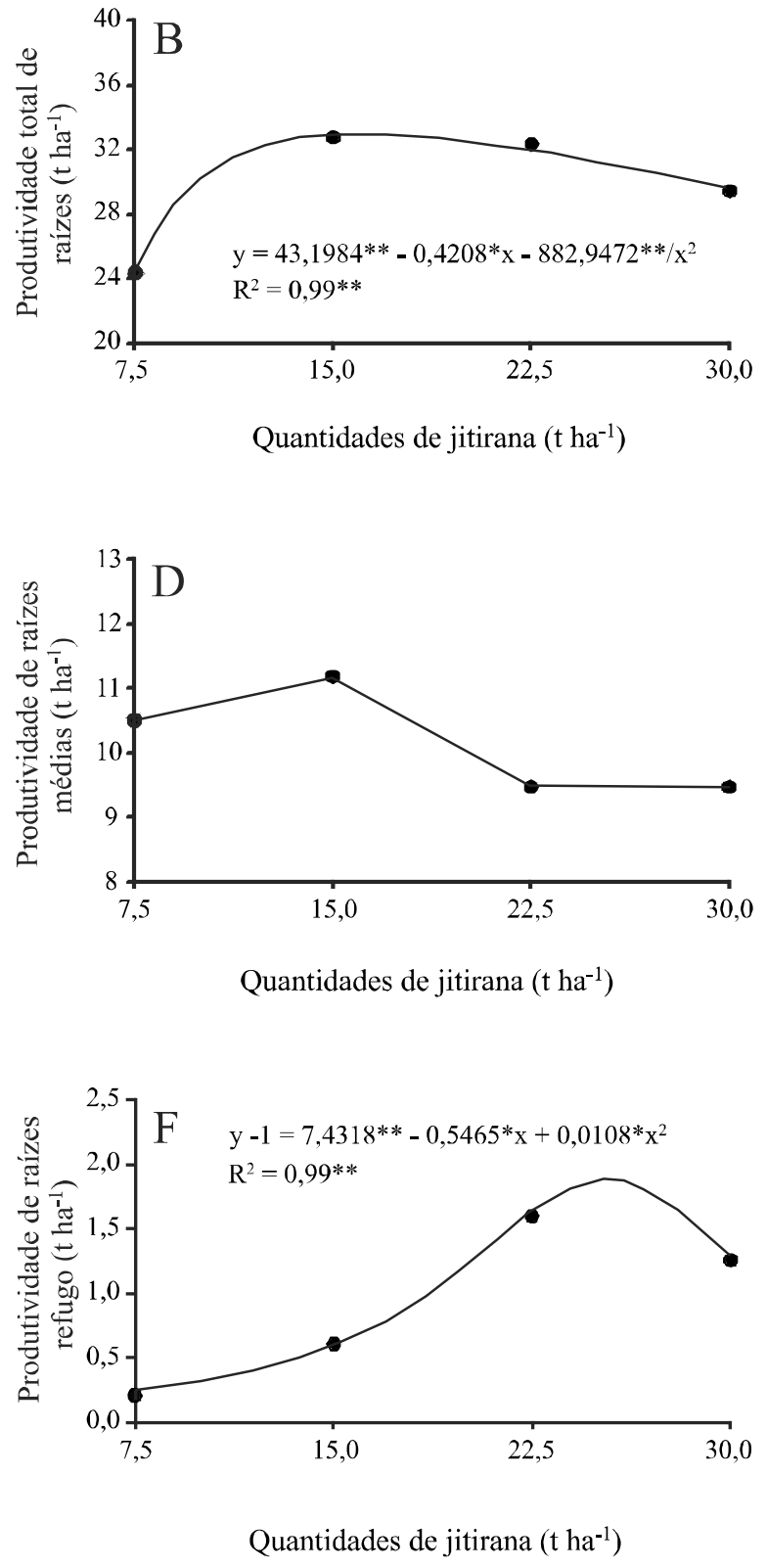

até a última dose de jitirana adicionada (Figuras 3A a 3D). Diante disso, observa-se, que a otimização do desempenho econômico da cenoura foi obtida com a incorporação da dose de jitirana ao redor de $13 \mathrm{t} \mathrm{ha}^{-1}$, ditada pela renda líquida, considerada um dos indicadores que expressa melhor o valor econômico dos sistemas de cultivos, do que a renda bruta, já que naquela se encontram deduzidos os custos de produção (BEZERRANETO et al., 2012). Esses resultados se devem ao fato de que a cenoura respondeu muito bem à adubação verde, e que esses indicadores econômicos promissores advieram do 
Figura 3 - Renda bruta, renda líquida, taxa de retorno e índice de lucratividade de cenoura solteira em função de quantidades de jitirana incorporadas ao solo
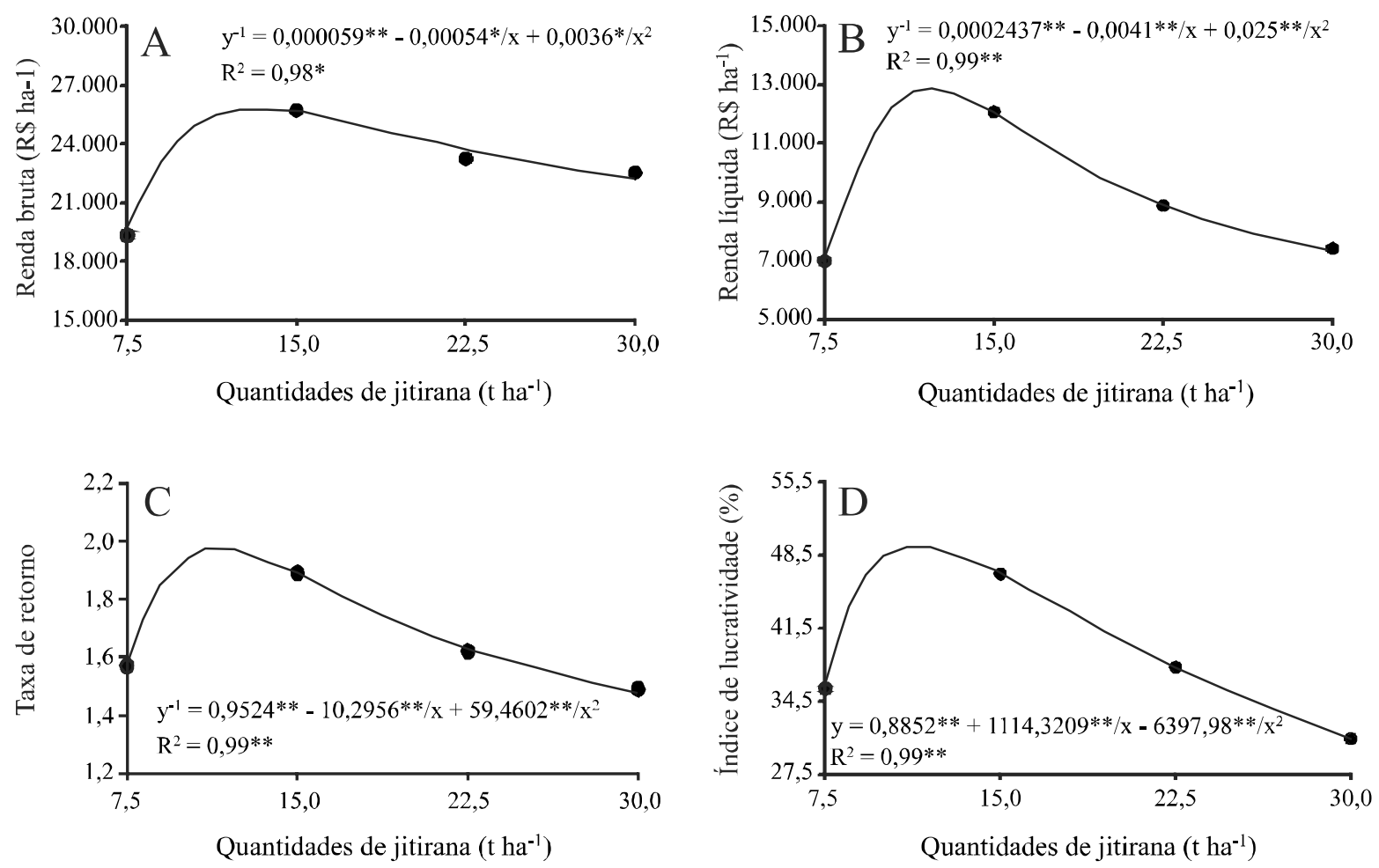

melhor aproveitamento dos recursos ambientais pelas plantas de cenoura proporcionadas pelas doses de jitirana testadas. Assim, a eficiência agronômica do desempenho produtivo da cenoura foi traduzida em eficiência econômica.

\section{CONCLUSÕES}

1.A otimização do desempenho agroeconômico da cenoura em cultivo solteiro é viabilizada com a incorporação de $13 \mathrm{t} \mathrm{ha}^{-1}$ de jitirana ao solo;

2. O cultivo da cenoura é viável agroeconomicamente com o uso da jitirana como adubo verde.

\section{REFERÊNCIAS}

BATISTA, M. A. V. Adubação verde na produtividade, qualidade $\mathrm{e}$ rentabilidade de beterraba e rabanete. 2011. 123 f. Tese (Doutorado em Agronomia: Fitotecnia) - Universidade Federal Rural do Semi-Árido (UFERSA), Mossoró, 2011.

BEZERRA NETO, F. et al. Desempenho agronômico da alface em diferentes quantidades e tempos de decomposição

de jitirana verde. Revista Brasileira de Ciências Agrárias, v. 6, n. 2, p. 236-242, 2011.

BEZERRA NETO, F. et al. Assessment of agroeconomic indices in polycultures of lettuce, rocket and carrot through uni- and multivariate approaches in semi-arid Brazil. Ecological Indicators, v. 14, p. 11-17, 2012.

BRAGA, R. Plantas do Nordeste, especialmente do Ceará. 3 ed. Fortaleza: ESAM. v. XLII. 540 p. 1976.

CORREIA, M. P. Dicionário das Plantas Úteis. v. 4. Mossoró: ESAM, 1984.

EMBRAPA - EMPRESA BRASILEIRA DE PESQUISA AGROPECUÁRIA. Centro Nacional de Pesquisa de solos. Sistema brasileiro de classificação de solos. $2^{\text {a }}$ ed. Rio de Janeiro: EMBRAPA, 2006. 306 p.

FIGUEIREDO NETO, A. et al. Efeito do composto orgânico nas características físico-químicas de cenoura "Brasília". Revista Brasileira de Produtos Agroindustriais, v. 12, n. 1, p. 61-66, 2010.

FONTANÉTTI, A. et al. Adubação verde na produção de alface americana e repolho. Horticultura Brasileira, v. 24, n. 2, p.146-150, 2006.

GÓES, S. B. Desempenho agroeconômico de alface lisa em função de quantidades de jitirana incorporadas ao solo e 
de seus tempos de decomposição. 2007. 84 f. Dissertação (Mestrado em Fitotecnia) - Universidade Federal Rural do Semi-Árido (UFERSA), Mossoró, 2007.

LANA, M. M; VIEIRA, J. V. Fisiologia e manuseio pós-colheita de cenoura. Brasília, EMBRAPA - Hortaliças. 2000. 15 p.

LINHARES, P. C. F. et al. Avaliação da decomposição da jitirana em cobertura no desempenho agronômico de rúcula. Revista Caatinga, v. 22, n. 3, p. 71-76, 2009.

LINHARES, P.C. F. et al. Quantidades e tempos de decomposição da jitirana no desempenho agronômico do coentro. Ciência Rural, v. 42, n. 2, p. 243-248, 2012.

LOPES, W. A. R . et al. Produtividade de cultivares de cenoura sob diferentes densidades de plantio. Revista Ceres, v. 55, n. 5 , p. $482-487,2008$.
MOREIRA, J. N. Consorciação de rúcula e coentro adubada com espécie espontânea sucedida pelo cultivo de rabanete. $2011.115 \mathrm{f}$. Tese (Doutorado em Agronomia: Fitotecnia) - Universidade Federal Rural do Semi-Árido (UFERSA), Mossoró, 2011.

OLIVEIRA, M. K. T. et al. Desempenho agronômico da cenoura adubada com jitirana antes de sua semeadura. Revista Ciência Agronômica, v. 42, n. 2, p. 364-372, 2011.

PAULA JÚNIOR, T. J.; VENZON, M. 101 culturas: Manual de tecnologias agrícolas. Belo Horizonte: EPAMIG, 2007. 800 p.

SILVA, M. L. et al. Produção de beterraba fertilizada com jitirana em diferentes doses e tempos de incorporação ao solo. Revista Brasileira de Engenharia Agrícola e Ambiental, v. 15, n. 8, p. 801-809, 2011.

VALE, F. R. et al. Fertilidade do solo: dinâmica e disponibilidade dos nutrientes de plantas. Lavras: Editora UFLA, 2004. 171 p. 